\title{
BRAND IMAGE MEMEDIASI HUBUNGAN E-COMMERCE DENGAN KEPUTUSAN PEMBELIAN KONSUMEN
}

\author{
Ni Kadek Anggi Pratiwi ${ }^{1}$ \\ Ni Wayan Ekawati ${ }^{2}$ \\ ${ }^{1,2}$ Fakultas Ekonomi dan Bisnis Universitas Udayana (Unud), Bali, Indonesia \\ email: anggipratiwi77@yahoo.com
}

\begin{abstract}
ABSTRAK
Pariwisata di Bali berkembang semakin pesat sehingga persaingan penyedia jasa penginapan juga semakin ketat, mulai dari hostel hingga resort mewah. Tujuan dari penelitian ini adalah untuk menjelaskan pengaruh e-commerce terhadap keputusan pembelian, e-commerce terhadap brand image, brand image terhadap keputusan pembelian, dan peran brand image memediasi hubungan e-commerce dengan keputusan pembelian. Penelitian ini dilakukan pada konsumen hotel THE HAVEN Bali Seminyak yang memesan kamar hotel menggunakan website resmi hotel. Ukuran sampel yang diambil sebanyak 136 responden dengan metode purposive sampling. Teknik analisis yang digunakan adalah analisis path. Hasil penelitian menemukan bahwa e-commerce berpengaruh positif dan signifikan terhadap brand image. Penelitian ini juga menemukan bahwa masing-masing variabel, yaitu $e-$ commerce dan brand image berpengaruh positif dan signifikan terhadap keputusan pembelian. Brand image juga berperan sebagai pemediasi hubungan antara e-commerce terhadap keputusan pembelian.
\end{abstract}

Kata kunci : e-commerce, brand image, keputusan pembelian

\begin{abstract}
The development of tourism in Bali is growing more rapidly so that the competition of lodging service providers is also getting tougher. Purpose of this study is to explain the effect of ecommerce on purchasing decisions, e-commerce on brand image, brand image on purchasing decisions, and the role of brand image mediating the relationship of e-commerce with purchasing decisions. This research was conducted on THE HAVEN Bali Seminyak hotel customers who book hotel rooms using the hotel's official website. 136 people are used as respondents with purposive sampling method and analyzed using path analysis. The results found that e-commerce had positive and significant effect on brand image. This study also found that each variable, e-commerce and brand image significantly had positive effect on purchasing decisions, in addition to that brand image also significantly mediated the relationship of e-commerce to purchasing decisions.

Keywords: e-commerce, brand image, purchase decision
\end{abstract}




\section{PENDAHULUAN}

Perkembangan teknologi semakin tidak bisa dibendung di zaman digital seperti saat ini. Segala aspek kehidupan manusia kini tidak ada yang lepas dari perkembangan teknologi (Arif, 2019). Perkembangan teknologi adalah sebuah keniscayaan yang tidak bisa dibatasi, karena pada hakikatnya, kehidupan ini akan selalu berkembang dan terus berkembang dari segala sisinya. Tujuan dari pengembangan teknologi ini adalah untuk semakin memudahkan manusia dalam memenuhi kebutuhannya dan juga sekaligus meningkatkan kualitas produk yang ditawarkan oleh perusahaan, termasuk dalam hal perdagangan (Ghoribi \& Djoko, 2018)

Pemanfaatan teknologi informasi dan komunikasi dalam bidang perniagaan telah berkembang dengan sangat pesat melalui sejumlah perubahan yang sangat signifikan dalam bentuk digitalisasi, mobilitas modal dan liberalisasi. Mekanisme dan proses transaksi bisnis semua dapat berlangsung secara online sehingga memudahkan dalam proses transaksi pembayarannya baik dalam negeri maupun luar negeri (Srisadono, 2018), dengan kemudahan tersebut diharapkan tingkat penjualan suatu perusahaan semakin baik.

Tingkat keputusan pembelian konsumen dapat dilihat dari tinggi atau rendahnya penjualan suatu perusahaan. Keputusan pembelian adalah tahap dalam proses pengambilan keputusan pembeli dimana konsumen benar-benar akan membeli (Lin \& Chuang, 2018). Keputusan konsumen dalam membeli atau tidaknya suatu produk dilakukan setelah melalui proses pengenalan kebutuhan, pencarian informasi dan evaluasi alternatif, ada lima tahap dalam proses keputusan pembelian yaitu, pengenalan kebutuhan, pencarian informasi, evaluasi alternatif, keputusan pembelian dan perilaku pasca pembelian. Semakin tinggi tingkat keputusan pembelian yang dilakukan oleh konsumen, maka semakin tinggi juga tingkat penjualan yang dicapai (Ghoribi \& Djoko, 2018). Salah satu variabel yang dapat merangsang keputusan konsumen dalam membeli suatu produk adalah electronic commerce.

Internet sebagai teknologi informasi berkembang yang mutakhir, kini penggunaannya telah merambah ke semua sektor kehidupan dan tidak dapat dipisahkan dari gaya hidup masyarakat saat ini. Salah satu peluang yang memanfaatkan teknologi internet di sektor bisnis adalah dengan menggunakan perdagangan elektronik (e-commerce) sebagai media perdagangan yang setiap orang dapat mengaksesnya di mana saja dan kapan saja (Puspitasari, 2018). Electronic commerce (perdagangan elektronik) adalah istilah umum untuk proses membeli dan menjual yang didukung oleh sarana-sarana elektronik (Baubonienè \& Gulevičiūtè, 2015). E-commerce menawarkan kemudahan bagi konsumen dan produsen dalam melakukan transaksi jual beli dari mulai proses pemilihan barang hingga proses pembayaran (Ghoribi \& Djoko, 2018). Memasarkan produk dengan menggunakan e-commerce dapat menciptakan citra merek atau brand image kepada konsumen secara tidak langsung, karena dengan memasarkan produk melalui $e$ commerce seperti media sosial dan website pribadi dapat membangun brand image kepada konsumen melalui media sosial para konsumen (Agustyan, 2017)

Semakin baik brand image yang dimiliki perusahaan maka keputusan konsumen untuk melakukan pembelian melalui situs online (e-commerce) juga 
akan semakin tinggi. Diperkuat dengan hasil penelitian yang dilakukan oleh Gunawan et al. (2019) yang berjudul Factors That Influence Purchase Decision in E-Commerce in Jakarta and Tangerang, menunjukkan bahwa salah satu faktor yang memengaruhi keputusan pembelian dalam e-commerce secara positif dan signifikan adalah brand image. Faktor brand image memiliki nilai lebih tinggi dibandingkan dengan faktor lainnya yang diuji, seperti harga dan kepercayaan dalam memengaruhi konsumen untuk melakukan keputusan pembelian pada situs $e$ commerce.

Citra Merek merupakan hal penting yang perlu diperhatikan perusahaan. Konsumen cenderung menjadikan citra merek (brand image) sebagai acuan sebelum melakukan pembelian suatu produk/jasa, maka perusahaan harus mampu menciptakan citra merek yang menarik sekaligus menggambarkan manfaat produk yang sesuai dengan keinginan dan kebutuhan konsumen sehingga dengan demikian konsumen memiliki citra yang positif terhadap merek (Fouratama \& Arifin, 2018). Bagi pemasar, apa pun strategi pemasaran perusahaan, tujuan utama dari kegiatan pemasaran mereka adalah untuk mempengaruhi persepsi dan sikap konsumen terhadap suatu merek, membangun citra merek di benak konsumen, dan merangsang perilaku pembelian aktual konsumen terhadap merek, dengan demikian dapat meningkatkan penjualan, memaksimalkan pangsa pasar dan mengembangkan ekuitas merek (Zhang, 2015). Brand image merupakan aspek penting yang memiliki hubungan dengan produk dan merupakan hal yang akan diperhatikan oleh konsumen dalam mengambil keputusan pembelian (Setiadi \& Ekawati, 2019)

Salah satu hotel bintang empat di daerah Seminyak, THE HAVEN Bali Seminyak, juga telah menerapkan sistem e-commerce sejak awal hotel didirikan tahun 2009. Hotel tersebut telah memiliki website penjualan sendiri untuk memudahkan konsumen melakukan pemesanan kamar secara online, tidak hanya dengan website resmi hotel, THE HAVEN Bali Seminyak juga bekerjasama dengan platform penjualan online lainnya seperti traveloka, agoda, expedia, booking.com, tiket.com, hotels.com, mister aladin, pegipegi, dan lain sebagainya.

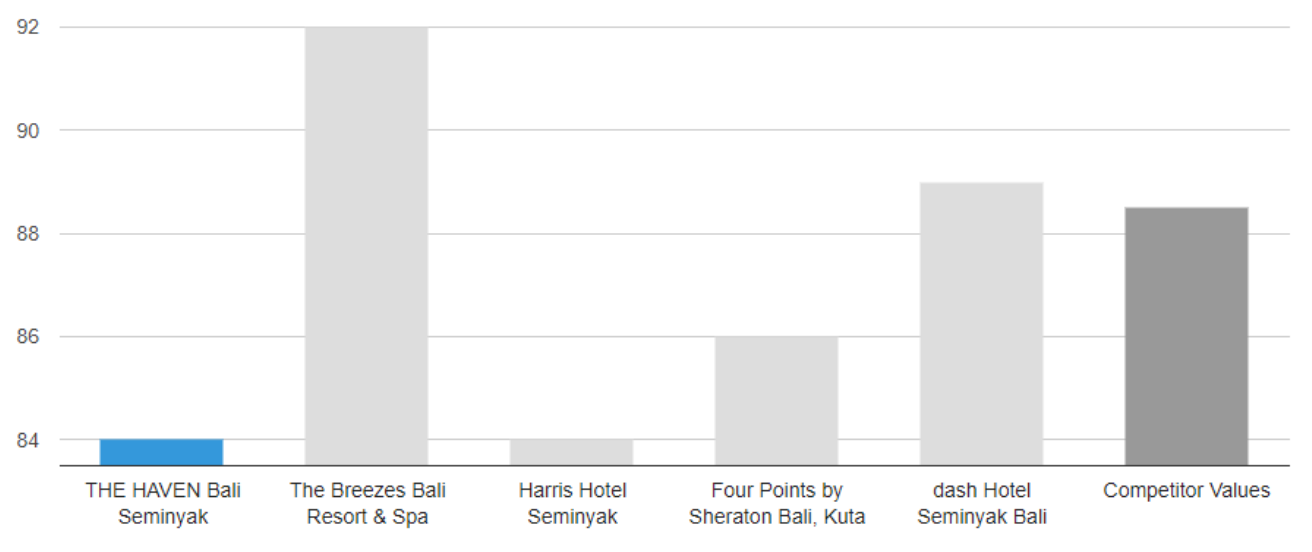

Gambar 1. Popularitas Hotel THE HAVEN Bali Seminyak Sumber: TrustYou, 2019 
Banyaknya platform penjualan online yang bermunculan membuat hotel THE HAVEN Bali Seminyak harus tetap menjaga kualitas website resmi hotel yang dimiliki agar jumlah konsumen yang memesan kamar melalui website resmi hotel bisa terus meningkat, karena jika dilihat dari kepopularan brand hotel yang dimiliki saat ini, hotel THE HAVEN Bali Seminyak belum mampu menjadi yang terbaik, seperti pada Gambar 1.

Gambar 1. menunjukkan bahwa hotel THE HAVEN masih menduduki posisi terakhir dalam hal kepopularitasannya dengan presentase 84 persen dimana pesaingnya memiliki nilai rata-rata bersaing sebesar 88,5 persen. Hasil presentase tersebut didapat berdasarkan hasil analisis yang dilakukan oleh TrustYou. TrustYou adalah Guest Feedback and Hotel Reputation Software, dimana TrustYou telah bekerja dengan 170+ feedback experts dan beroperasi dari 5 kantor yang berada di Amerika Serikat, Eropa dan Asia dengan tujuan untuk membantu perusahaan agar berhasil dengan kekuatan feedback konsumen. TrustYou juga telah mengumpulkan 18 juta survei tamu, 700 juta ulasan yang telah dianalisis, dan memiliki 700 ribu database hotel di seluruh dunia.

Peningkatan bersaing dapat dilakukan dengan menciptakan situs penjualan online yang menarik, mudah dan memberikan banyak kelebihan dibandingkan dengan hotel lain. Selain itu, membangun citra merek hotel juga menjadi salah satu strategi yang harus diperhatikan sebaik mungkin oleh pihak hotel agar dapat bersaing dengan pesaing hotel lainnya, seperti reviews online oleh konsumen harus dijaga agar tetap mendapat reviews yang positif, dengan demikian diharapkan keputusan pembelian oleh konsumen bisa meningkat tiap tahunnya.

Permasalahan yang kerap terjadi ketika menginap di suatu hotel adalah masalah booking-an kamar yang tidak terdaftar atau tidak sesuai antara yang dimiliki oleh konsumen dengan hotel. Begitu pula yang terjadi pada hotel THE HAVEN Bali Seminyak, dalam kegiatan e-commerce, proses booking menjadi salah satu kendala yang cukup serius dan sering terjadi, seperti yang terlihat pada Gambar 2.

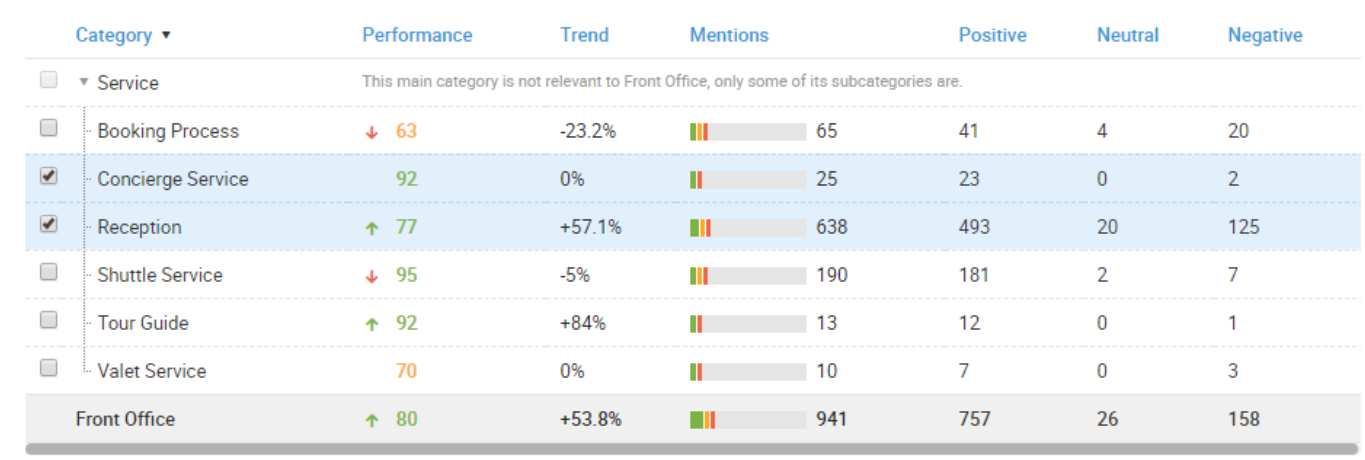

Gambar 2. Analisis Aspek Front Office hotel THE HAVEN Bali Seminyak Sumber: TrustYou, 2019

Berdasarkan Gambar 2. dapat dijelaskan bahwa permasalahan dalam bidang e-commerce, yakni proses booking, menjadi masalah kedua yang banyak mendapat review negatif dari konsumen hotel THE HAVEN Bali Seminyak setelah reception. Proses booking mendapat komentar negatif sebanyak 20 kali dalam kurun waktu 
kurang lebih 1 tahun (2018 - Oktober 2019). Hal ini menunjukkan bahwa $e$ commerce yang dimiliki hotel THE HAVEN Bali Seminyak dalam kegiatan pemesanan kamar hotel belum maksimal dan banyak konsumen yang masih merasa kesulitan dalam proses pemesanan kamar tersebut, terbukti dari reviews yang ditulis oleh beberapa konsumen pada situs reviews online TrustYou.

Berdasarkan Tabel 1. dapat dilihat bahwa tidak sedikit konsumen yang merasa kecewa karena ketidaksesuaian booking-an kamar yang dimiliki konsumen dengan hotel kerap kali terjadi, seperti terjadinya double booking, booking tidak terdaftar dalam sistem hotel, kesalahan fasilitias yang didapat dan tidak sesuai pesanan, dan lain sebagainya. Hal ini menunjukkan bahwa e-commerce yang dimiliki hotel THE HAVEN Bali Seminyak masih belum maksimal dan perlu diperhatikan lebih baik lagi agar proses booking dapat berjalan dengan lancar dan tepat, dengan demikian diharapkan ketidaksesuaian booking-an dapat diminimalisir dan mampu meningkatkan tingkat keputusan konsumen untuk melakukan pemesanan kamar pada hotel THE HAVEN Bali Seminyak.

Tabel 1.

Reviews Negatif Mengenai Proses Booking

\begin{tabular}{|c|c|c|c|}
\hline No & Skor & Website & Reviews \\
\hline \multirow[t]{6}{*}{1} & $75 / 100$ & Booking.com & Good \\
\hline & & 23-01-2019 & Good value for money. I have a feeling the service \\
\hline & & Eben & level have gone down. We have stayed here a number \\
\hline & & & of times, but it feels like the standards have slipped a \\
\hline & & & little bit. We had issues with our rooms, multiple \\
\hline & & & $\begin{array}{l}\text { bookings, issues with maintenance (of which we were } \\
\text { not notified prior to our arrival)... }\end{array}$ \\
\hline \multirow[t]{3}{*}{2} & $60 / 100$ & Agoda & Disappointed Stay \\
\hline & & $08-11-2018$ & Glad we didn't pay full price as the booking was \\
\hline & & Mandi & $\begin{array}{l}\text { messed up from the start. This hotel is not } 4 \text { stars.. } \\
\text { maybe pushing } 3 \text { stars at most... }\end{array}$ \\
\hline \multirow[t]{3}{*}{3} & $40 / 100$ & TripAdvisor & Don't bother \\
\hline & & $30-10-2018$ & I had four nights here, two at the beginning and end of \\
\hline & & 192Jen & $\begin{array}{l}\text { an organized tour that took us to other parts of the } \\
\text { island. Twice the couldn't find my booking \& I had to } \\
\text { show them my booking receipt email... }\end{array}$ \\
\hline \multirow[t]{3}{*}{4} & $40 / 100$ & TrustYou Survey & We arrived to be told breakfast was not included in \\
\hline & & $09-10-2018$ & the booking. I showed the itinerary which showed it \\
\hline & & Debra L. & $\begin{array}{l}\text { was included and was told I had to take it up with my } \\
\text { booking agency... }\end{array}$ \\
\hline \multirow[t]{3}{*}{5} & $20 / 100$ & TripAdvisor & Terrible management and staff \\
\hline & & $05-10-2018$ & Terrible management. When I arrived, the hotel had \\
\hline & & Ai-007 & $\begin{array}{l}\text { the wrong booking and the mentioned they could do } \\
\text { nothing about it. Was kept waiting at the reception for } \\
\text { over } 30 \text { minutes as the reception confirmed the } \\
\text { booking situation with their e-commerce team... }\end{array}$ \\
\hline
\end{tabular}

Sumber: TrustYou, 2019

Penelitian sebelumnya yang dilakukan oleh Putra \& Wulandari (2015) menyatakan bahwa e-commerce hanya sebesar 17,1 persen secara signifikan memengaruhi keputusan pembelian. Sedangkan menurut Ghoribi \& Djoko (2018) 
menyatakan e-commerce memengaruhi keputusan pembelian sebesar 27,4 persen secara signifikan. Hasil peneilitian yang dilakukan oleh Foster (2016) menyatakan bahwa brand image hanya memengaruhi keputusan pembelian sebesar 7 persen. Sedangkan menurut Fouratama \& Arifin (2018) menyatakan bahwa brand image memengaruhi keputusan pembelian secara signifikan sebesar 67 persen.

Berdasarkan pokok permasalahan tersebut, adapun rumusan masalah dalam penelitian ini, antara lain: 1) Bagaimana pengaruh $e$-commerce terhadap keputusan pembelian pada hotel THE HAVEN Bali Seminyak? 2) Bagaimana pengaruh $e$ commerce terhadap brand image pada hotel THE HAVEN Bali Seminyak? 3) Bagaimana pengaruh brand image terhadap keputusan pembelian konsumen pada hotel THE HAVEN Bali Seminyak? 4) Bagaimana peran brand image memediasi hubungan e-commerce dengan keputusan pembelian konsumen pada hotel THE HAVEN Bali Seminyak?

Tujuan dari penelitian ini adalah: 1) Untuk menjelaskan pengaruh $e$ commerce terhadap keputusan pembelian pada hotel THE HAVEN Bali Seminyak, 2) Untuk menjelaskan pengaruh e-commerce terhadap brand image pada hotel THE HAVEN Bali Seminyak, 3) Untuk menjelaskan pengaruh brand image terhadap keputusan pembelian pada hotel THE HAVEN Bali Seminyak, 4) Untuk menjelaskan peran brand image memediasi hubungan e-commerce dengan keputusan pembelian pada hotel THE HAVEN Bali Seminyak.

Hasil penelitian ini diharapkan dapat memberikan manfaat bagi dunia ilmu pengetahuan khususnya manajemen pemasaran serta mampu menjadi bahan referensi untuk bahan penelitian dalam kajian peran brand image memediasi hubungan e-commerce dengan keputusan pembelian, dan juga diharapkan mampu menjadi bahan pertimbangan bagi hotel THE HAVEN Bali Seminyak untuk pengambilan keputusan terkait peningkatan brand image yang baik agar konsumen membuat keputusan pembelian melalui situs e-commerce yang dimiliki hotel. Adapun hipotesis penelitian ini, antara lain:

$\mathrm{H}_{1}$ : E-Commerce berpengaruh positif dan signifikan terhadap keputusan pembelian

Shahjee (2016) mendefinisikan e-commerce sebagai penggunaan internet dan Web dalam melakukan transaksi bisnis dan e-commerce secara digital mampu mempermudah transaksi komersial antar organisasi dan antara organisasi dengan individu. Menurut Agustyan (2017) dalam penelitiannya mengenai pengaruh $e$ commerce terhadap keputusan pembelian menunjukkan bahwa e-commerce memiliki pengaruh positif dan signifikan terhadap keputusan pembelian. Selaras dengan Putra \& Wulandari (2015) dalam penelitiannya yang berjudul "Pengaruh penerapan $e$-commerce terhadap keputusan pembelian (studi kasus pada pengguna STEAM Valve)" menyatakan bahwa e-commerce berpengaruh positif terhadap keputusan pembelian. Begitu pula dengan penelitian yang dilakukan oleh Xiao et al. (2019) menunjukkan hasil bahwa penerapan e-commerce memiliki pengaruh positif dan signifikan terhadap keputusan pembelian produk.

$\mathrm{H}_{2}$ : E-Commerce berpengaruh positif dan signifikan terhadap Brand Image

Memasarkan produk dengan menggunakan e-commerce dapat menciptakan citra merek atau brand image kepada konsumen secara tidak langsung, karena dengan memasarkan produk melalui e-commerce seperti media sosial atau website pribadi dapat membangun brand image kepada konsumen melalui media sosial para 
konsumen. Hasil penelitian yang dilakukan oleh Gunawan et al. (2019) yang berjudul Factors That Influence Purchase Decision in E-Commerce in Jakarta and Tangerang, menunjukkan bahwa salah satu faktor yang memengaruhi keputusan pembelian dalam e-commerce secara positif dan signifikan adalah brand image. Gunawan et al. (2019) menggunakan 3 variabel untuk mengukur faktor yang memengaruhi keputusan pembelian dalam penggunaan e-commerce, yakni brand image, trust dan price dengan penyebaran 200 kuesioner kepada konsumen yang telah melakukan belanja online di Jakarta dan Tangerang. Hasil yang didapat adalah hanya faktor brand image yang mendapat hasil positif dan signifikan dalam memengaruhi keputusan pembelian, sedangkan 2 faktor lainnya, trust dan price, tidak memengaruhi keputusan pembelian dalam e-commerce. Hasil penelitian Kidane \& Sharma (2016) yang berjudul Factor Affecting Consumers' Purchasing Decision through E-Commerce menyatakan bahwa salah satu faktor yang memengaruhi keputusan pembelian dalam e-commerce adalah citra merek yang dimiliki perusahaan.

$\mathrm{H}_{3} \quad$ : Brand Image berpengaruh positif dan signifikan terhadap keputusan pembelian

Citra merek adalah sekumpulan asosiasi merek yang terbentuk dan melekat di benak konsumen. Konsumen yang mempunyai citra positif terhadap merek cenderung memilih merek tersebut dalam pembelian. Penelitian Yasmin (2017) yang berjudul Impact of Brand Image on Cunsomers' Purchase Decision menunjukkan bahwa citra merek berpengaruh positif signifikan terhadap keputusan pembelian. Begitu juga dengan Kurniawan (2018) yang meneliti tentang Pengaruh Citra Merek terhadap Keputusan Pembelian (Survei Kepada Para Siswa SMAN 15 Surabaya Kelas XII yang Menggunakan Laptop Ber-Merek ASUS), dimana citra merek berpengaruh positif signifikan terhadap keputusan pembelian. Hasil penelitian dari Moh (2018) yang berjudul Effect of Brand Image and Price Perception on Purchase Decision menunjukkan bahwa dalam penelitian tersebut citra merek secara simultan berpengaruh positif dan signifikan terhadap keputusan pembelian. Penelitian yang dilakukan oleh Lubis \& Hidayat (2017) yang berjudul Pengaruh Citra Merek dan Harga terhadap Keputusan Pembelian pada Sekolah Tinggi Ilmu Manajemen Sukma Medan, menyatakan bahwa citra merek berpengaruh positif dan signifikan terhadap keputusan pembelian. Penelitian yang berjudul Impact of Brand Image on Purchasing Decision on Mineral Water Product "Amidis" oleh Foster (2016) juga menyatakan bahwa brand image berpengaruh positif terhadap keputusan pembelian.

$\mathrm{H}_{4} \quad$ : Brand image berperan secara signifikan dalam memediasi hubungan $e$ commerce terhadap keputusan pembelian

Semakin kuat brand image, semakin tinggi pula kainginan konsumen untuk bergantung pada merek berdasarkan pada keyakinan atau harapan yang dihasilkan dari kredibilitas, kebajikan dan kemampuan merek tersebut terkait kinerja lingkungannya. Menurut Iswara \& Jatra (2017) dalam penelitiannya menunjukkan bahwa brand image dinilai secara signifikan mampu memediasi pengaruh E-wom terhadap keputusan pembelian. Penelitian oleh Ardana \& Rastini (2018) menyatakan bahwa brand image dapat memediasi pengaruh $E$-wom terhadap minat beli konsumen. Penelitian lainnya yang dilakukan oleh Eriza (2017) menyatakan 
bahwa citra merek memediasi secara parsial hubungan E-Wom dan minat beli pada E-Commerce.

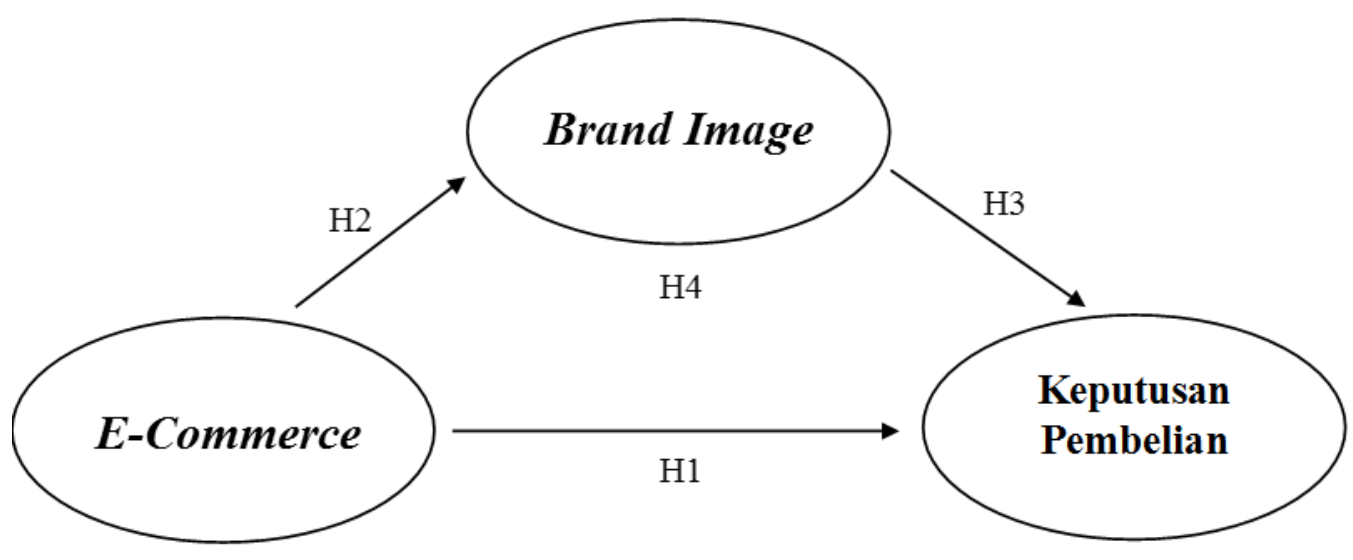

Gambar 3. Kerangka Konseptual

Gambar 3. menjelaskan bahwa variabel yang digunakan adalah variabel ecommerce, brand image, dan keputusan pembelian.

\section{METODE PENELITIAN}

Penelitian ini dilakukan di hotel THE HAVEN Bali Seminyak. Hotel THE HAVEN Bali Seminyak dipilih sebagai lokasi penelitian dengan pertimbangan bahwa hotel THE HAVEN Bali Seminyak merupakan hotel bintang 4 yang meraih skor sebesar 84 dengan kategori sangat baik berdasarkan analisis reviews online yang dilakukan oleh TrustYou hingga tahun 2019, namun untuk kepopularitasannya hotel ini masih tergolong rendah yakni berada pada urutan ke 88 dari 150 hotel bintang 4 di daerah Badung. Selain itu, daerah Seminyak adalah salah satu kawasan ramai wisatawan di kabupaten Badung.

Jenis data untuk penelitian ini ada 2 (dua), yakni data kualitatif, yakni pendapat responden terhadap pernyataan yang meliputi e-commerce, citra merek, dan keputusan pembelian, dan data kuantitatif, yakni meliputi usia responden, pendapatan responden dan data ordinal yang dikuantifisir. Berdasarkan sumbernya, data yang digunakan dalam penelitian ini adalah data primer, yakni para responden yang sesuai dengan kriteria sampel dan didapat dari tanggapan responden secara langsung terhadap variabel-variabel penelitian yang akan diuji yaitu mengenai $e$ commerce, brand image, dan keputusan pembelian, dan data sekunder, yakni bukubuku dan artikel yang berkaitan dengan pembahasan masalah ini atau informasi yang relevan dengan pembahasan.

Pada penelitian ini, subjek penelitiannya adalah orang yang pernah melakukan pemesanan kamar hotel THE HAVEN Bali Seminyak melalui situs penjualan online hotel THE HAVEN Bali Seminyak setidaknya satu kali. Objek penelitiannya adalah pengaruh variabel $e$-commerce terhadap keputusan pembelian produk hotel THE HAVEN Bali Seminyak dengan brand image sebagai variabel mediasinya. 
Penelitian ini menggunakan 3 jenis variabel, antara lain: variabel eksogen, yaitu e-commerce (X), variabel mediasi yaitu brand image (Y1), dan variabel endogen yaitu keputusan pembelian (Y2). Definisi operasional variabel dalam penelitian ini dapat dilihat pada Tabel 2.

Tabel 2.

Definisi Operasional Variabel

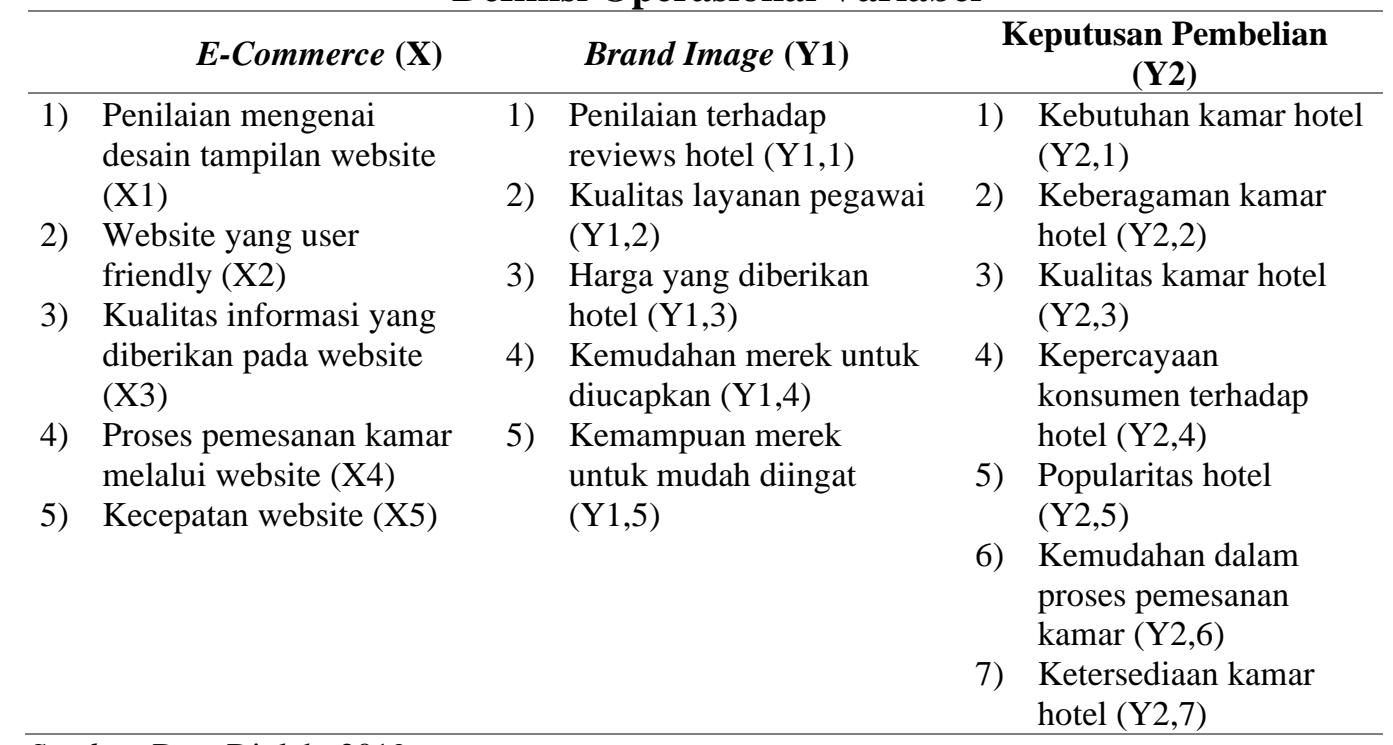

Sumber: Data Diolah, 2019

Populasi dalam penelitian ini adalah konsumen hotel THE HAVEN Bali Seminyak. Penelitian ini menggunakan 136 responden dari konsumen yang pernah memesan kamar hotel THE HAVEN Bali Seminyak menggunakan website resmi hotel. Kriteria penentuan sampel dalam penelitian ini adalah: 1) Responden minimal berumur 17 tahun (per tahun 2019), 2) merupakan wisatawan lokal dan asing, 3) mengetahui hotel THE HAVEN Bali Seminyak, 4) pernah mengunjungi website resmi hotel THE HAVEN Bali Seminyak dan memesan kamar hotel THE HAVEN Bali Seminyak setidaknya satu kali. Metode pengumpulan data dalam penelitian ini adalah metode survei dengan menggunakan kuesioner, dimana kuesioner disebarluaskan kepada responden. Pengukuran atas jawaban dari responden diukur dengan menggunakan skala likert. Teknik analisis yang digunakan dalam penelitian ini adalah teknik analisis jalur (path analysis), uji sobel, dan uji VAF.

\section{HASIL DAN PEMBAHASAN}

Hasil karakteristik responden dapat dilihat pada Tabel 3. Berdasarkan Tabel 3. hasil karakteristik responden diperoleh data, yaitu berdasarkan jenis kelamin, responden laki-laki sebesar 47 persen dan perempuan sebesar 53 persen. Berdasarkan usianya, responden dengan usia 26-35 tahun memiliki jumlah yang paling besar yakni sebesar 40 persen, responden berusia 17-25 tahun dan 36-45 
tahun memiliki skor yang sama sebesar 24 persen, dan yang terakhir memiliki skor sebesar 12 persen adalah responden dengan usia di atas 45 tahun.

Tabel 3.

\begin{tabular}{|c|c|c|c|}
\hline \multicolumn{4}{|c|}{ Karakteristik Responden Konsumen Hotel THE HAVEN Bali Seminyak } \\
\hline \multirow{2}{*}{ No. } & \multirow{2}{*}{ Jenis Kelamin } & \multicolumn{2}{|c|}{ Jumlah } \\
\hline & & Orang & Presentase $(\%)$ \\
\hline 1 & Laki-laki & 64 & 47 \\
\hline \multirow[t]{2}{*}{2} & Perempuan & 72 & 53 \\
\hline & Jumlah & 136 & 100 \\
\hline \multirow{2}{*}{ No } & \multirow{2}{*}{ Usia } & \multicolumn{2}{|c|}{ Jumlah } \\
\hline & & Orang & Presentase $(\%)$ \\
\hline 1 & 17-25 tahun & 32 & 24 \\
\hline 2 & 26-35 tahun & 55 & 40 \\
\hline 3 & $36-45$ tahun & 33 & 24 \\
\hline \multirow[t]{2}{*}{4} & $>45$ tahun & 16 & 12 \\
\hline & Jumlah & 136 & 100 \\
\hline \multirow{2}{*}{ No } & \multirow{2}{*}{ Pekerjaan } & \multicolumn{2}{|c|}{ Jumlah } \\
\hline & & Orang & Presentase $(\%)$ \\
\hline 1 & Pelajar/Mahasiswa & 22 & 16 \\
\hline 2 & Pegawai Negeri & 8 & 6 \\
\hline 3 & Pegawai Swasta & 68 & 50 \\
\hline 4 & Enterpreneur & 19 & 14 \\
\hline \multirow[t]{2}{*}{5} & Lainnya & 19 & 14 \\
\hline & Jumlah & 136 & 100 \\
\hline \multirow{2}{*}{ No } & Pendapatan per bulan & \multicolumn{2}{|c|}{ Jumlah } \\
\hline & Penaapatan per ouran & Orang & Presentase $(\%)$ \\
\hline 1 & $\leq \mathrm{Rp} 2.000 .000$ & 9 & 7 \\
\hline 2 & $\operatorname{Rp} 2.000 .000-\operatorname{Rp} 4.000 .000$ & 20 & 15 \\
\hline 3 & $\operatorname{Rp} 4.000 .000-\operatorname{Rp} 7.000 .000$ & 44 & 32 \\
\hline \multirow[t]{2}{*}{4} & $\geq \operatorname{Rp} 7.000 .000$ & 63 & 46 \\
\hline & Jumlah & 136 & 100 \\
\hline \multirow[t]{2}{*}{ No } & Awal mengetahui hotel & \multicolumn{2}{|c|}{ Jumlah } \\
\hline & Awar mengetanitur noter & Orang & Presentase $(\%)$ \\
\hline 1 & Teman & 39 & 29 \\
\hline 2 & Internet & 62 & 46 \\
\hline 3 & Televisi/Radio & 2 & 1 \\
\hline \multirow[t]{2}{*}{4} & Lainnya & 33 & 24 \\
\hline & Jumlah & 136 & 100 \\
\hline
\end{tabular}

Sumber: Data Diolah, 2019

Berdasarkan pekerjaan responden, pegawai swasta menduduki posisi pertama dengan presentase sebesar 50 persen, yang diikuti dengan pelajar/mahasiswa meraih presentase sebesar 16 persen, dan responden dengan pekerjaan sebagai entrepreneur dan lainnya memperoleh hasil yang sama yakni 14 persen, dan pegawai negeri mendapat hasil sebesar 6 persen.

Berdasarkan pendapatan per bulan responden, sebanyak 46 persen responden memiliki pendapatan di atas Rp 7.000.000, responden dengan pendapatan sebesar Rp 2.000.000 - Rp 4.000.000 dan Rp 4.000.000 - Rp 7.000.000 masing-masing sebanyak 15 persen dan 32 persen, serta sebesar 7 persen responden memiliki pendapatan di bawah Rp 2.000.000. Internet menjadi sumber tertinggi awal responden mengetahui hotel THE HAVEN Bali Seminyak dengan presentase 
sebesar 46 persen, diikuti dengan teman dan sumber lainnya masing-masing sebesar 29 persen dan 24 persen, serta hanya sebesar 1 persen responden menyatakan bahwa televisi/radio merupakan sumber awal mereka mengetahui hotel THE HAVEN Bali Seminyak.

Uji validitas bertujuan untuk memeriksa apakah kuesioner sebagai instrument penelitian sudah tepat untuk mengukur apa yang seharusnya diukur. Suatu instrumen dikatakan valid apabila memiliki koefisien korelasi antara butir dengan skor total dalam instrumen tersebut lebih besar dari 0,30. Hasil uji validitas pada Tabel 4 menunjukkan bahwa seluruh instrumen penelitian yang digunakan untuk mengukur variabel e-commerce, brand image, dan keputusan pembelian memiliki nilai koefisien korelasi dengan skor total seluruh item pernyataan lebih dari 0,30. Hal ini menunjukkan bahwa butir-butir pernyataan dalam instrumen penelitian tersebut valid dan layak digunakan sebagai instrumen penelitian.

Tabel 4.

Rekapitulasi Hasil Uji Validitas Instrumen Penelitian

\begin{tabular}{ccc}
\hline Variabel & Indikator & Koefisien Korelasi \\
\hline \multirow{2}{*}{ E-Commerce } & X1 & 0,823 \\
$(\mathrm{X})$ & $\mathrm{X} 2$ & 0,818 \\
& $\mathrm{X} 3$ & 0,893 \\
& $\mathrm{X} 4$ & 0,872 \\
Brand Image & $\mathrm{X} 5$ & 0,856 \\
(Y1) & Y1.1 & 0,722 \\
& Y1.3 & 0,758 \\
& Y1.4 & 0,689 \\
& Y1.5 & 0,771 \\
Keputusan Pembelian (Y2) & Y2.1 & 0,771 \\
& Y2.2 & 0,594 \\
& Y2.3 & 0,624 \\
& Y2.4 & 0,692 \\
& Y2.5 & 0,805 \\
& Y2.6 & 0,772 \\
& Y2.7 & 0,718 \\
\hline
\end{tabular}

Sumber: Data Diolah, 2019

Hasil uji reliabilitas yang disajikan dalam Tabel 5.

Tabel 5.

Rekapitulasi Uji Reliabilitas Instrumen Penelitian

\begin{tabular}{clc}
\hline No & \multicolumn{1}{c}{ Variabel } & Cronbach's Alpha \\
\hline 1 & E-Commerce & 0,896 \\
2 & Brand Image & 0,796 \\
3 & Keputusan Pembelian & 0,808 \\
\hline
\end{tabular}

Sumber: Data Diolah, 2019

Tabel 5. menunjukkan bahwa seluruh instrumen penelitian memiliki koefisien Cronbach's Alpha lebih dari 0,60. Jadi dapat dinyatakan bahwa seluruh 
variabel telah memenuhi syarat reliablitas atau kehandalan sehingga dapat digunakan untuk melakukan penelitian.

Pengujian data dalam penelitian ini menggunakan teknik analisis jalur (path analysis), dimana analisis jalur adalah perluasan dari analisis regresi linier berganda untuk menguji hubungan kualitas antara 2 atau lebih variabel.

Hasil analisis jalur substruktur 1 seperti yang disajikan pada Tabel 6, maka dapat dibuat persamaan struktural sebagai berikut:

$\mathrm{Y} 1=\beta 1 \mathrm{X}+\mathrm{e} 1=0,644 \mathrm{X}+\mathrm{e} 1$

Nilai keofisien regresi variabel e-commerce bernilai poisitif dengan nilai signifikan uji t kurang dari 0,05 . Hal ini menunjukkan bahwa variabel $e$-commerce memiliki pengaruh positif dan signifikan terhadap variabel brand image. Besarnya pengaruh variabel bebas terhadap variabel terikat yang ditunjukkan oleh nilai determinasi total ( $\mathrm{R}$ square) sebesar 0,415 mempunyai arti bahwa sebesar 41,5 persen variasi brand image dipengaruhi oleh variasi e-commerce. Sedangkan sisanya 58,5 persen dijelaskan oleh faktor lain yang tidak dimasukkan ke dalam model. Nilai koefisien beta sebesar 0,644 yang berarti bahwa apabila kehandalan e-commerce naik sebesar 1 persen maka brand image akan meningkat sebesar 0,644 persen.

Tabel 6.

Hasil Analisis Jalur 1

\begin{tabular}{|c|c|c|c|c|c|}
\hline \multirow{2}{*}{ Variabel } & \multicolumn{2}{|c|}{$\begin{array}{c}\text { Unstandardized } \\
\text { Coefficients }\end{array}$} & \multirow{2}{*}{$\begin{array}{c}\begin{array}{c}\text { Standardized } \\
\text { Coefficients }\end{array} \\
\text { Beta }\end{array}$} & \multirow{2}{*}{$\begin{array}{c}\text { t } \\
\text { hitung }\end{array}$} & \multirow{2}{*}{$\underset{t}{\text { Sig. uji }}$} \\
\hline & B & Std. Error & & & \\
\hline (Constant) & 2,123 & 0,207 & & 10,265 & 0,000 \\
\hline E-Commerce $(\mathrm{X})$ & 0,528 & 0,054 & 0,644 & 9,744 & 0,000 \\
\hline R Square & 0,415 & & & & \\
\hline F Statistik & 94,950 & & & & \\
\hline Sig. Uji F & 0,000 & & & & \\
\hline
\end{tabular}

Sumber: Data Diolah, 2019

Hasil analisis jalur substruktur 2 seperti yang disajikan Tabel 7, maka dapat dibuat persamaan struktural sebagai berikut.

$\mathrm{Y} 2=0,483 \mathrm{X}+0,269 \mathrm{Y} 1+\mathrm{e} 2$.

Nilai koefisien regresi masing-masing variabel bebas bernilai positif dengan nilai signifikansi uji t kurang dari 0,05 . Hal ini menunjukkan bahwa semua variabel bebas memiliki pengaruh positif dan signifikan terhadap variabel terikat.

Besarnya pengaruh variabel bebas terhadap variabel terikat yang ditunjukkan oleh nilai determinasi total ( $\mathrm{R}$ square) sebesar 0,473 mempunyai arti bahwa sebesar 47,3 persen variasi keputusan pembelian dipengaruhi oleh variasi e-commerce dan brand image, sedangkan sisanya sebesar 52,7 persen dijelaskan oleh faktor lain yang tidak dimasukkan ke dalam model. 
Tabel 7.

Hasil Analisis Jalur 2

\begin{tabular}{|c|c|c|c|c|c|}
\hline \multirow{2}{*}{ Variabel } & \multicolumn{2}{|c|}{$\begin{array}{c}\text { Unstandardized } \\
\text { Coefficients }\end{array}$} & \multirow{2}{*}{$\begin{array}{c}\begin{array}{c}\text { Standardized } \\
\text { Coefficients }\end{array} \\
\text { Beta }\end{array}$} & \multirow{2}{*}{$\begin{array}{c}\mathbf{t} \\
\text { hitung }\end{array}$} & \multirow{2}{*}{$\underset{t}{\text { Sig. uji }}$} \\
\hline & B & Std. Error & & & \\
\hline (Constant) & 0,913 & 0,304 & & 3,002 & 0,003 \\
\hline E-Commerce (X) & 0,457 & 0,078 & 0,483 & 5,869 & 0,000 \\
\hline Brand Image $(\mathrm{Y})$ & 0,311 & 0,095 & 0,269 & 3,274 & 0,001 \\
\hline R Square & 0,473 & & & & \\
\hline F Statistik & 59,728 & & & & \\
\hline Sig. Uji F & 0,000 & & & & \\
\hline
\end{tabular}
berikut:

Perhitungan pengaruh antar variabel dirangkum dalam Tabel 8. sebagai

Tabel 8.

Pengaruh Langsung dan Tidak Langsung serta Pengaruh Total E-Commerce (X), Brand Image (Y1), dan Keputusan Pembelian (Y2)

\begin{tabular}{cccc}
\hline Pengaruh Variabel & $\begin{array}{c}\text { Pengaruh } \\
\text { Langsung }\end{array}$ & $\begin{array}{c}\text { Pengaruh Tidak Langsung } \\
\text { melalui Brand Image } \\
(\mathbf{Y 1}) \\
(\boldsymbol{\beta 1} \mathbf{x} \boldsymbol{\beta 3})\end{array}$ & $\begin{array}{c}\text { Pengaruh } \\
\text { Total }\end{array}$ \\
\hline $\mathrm{X} \rightarrow \mathrm{Y} 1$ & 0,644 & & 0,644 \\
$\mathrm{X} \rightarrow \mathrm{Y} 2$ & 0,483 & 0,173 & 0,656 \\
$\mathrm{Y} 1 \rightarrow \mathrm{Y} 2$ & 0,269 & & 0,269 \\
\hline
\end{tabular}

Sumber: Data Diolah, 2019

Tabel 8. menunjukkan bahwa pengaruh langsung e-commerce $(\mathrm{X})$ terhadap brand image (Y1) adalah sebesar 0,644. Pengaruh langsung variabel $e$-commerce (X) terhadap keputusan pembelian (Y2) adalah 0,483. Pengaruh langsung variabel brand image (Y1) terhadap keputusan pembelian (Y2) sebesar 0,269. Hal ini menandakan bahwa variabel keputusan pembelian lebih besar dipengaruhi oleh $e$ commerce daripada brand image. Adapun pengaruh tidak langusng variabel $e$ commerce (X) terhadap keputusan pembelian (Y2) melalui brand image (Y1) adalah sebesar 0,656. Jadi, dapat disimpulkan bahwa lebih besar total pengaruh $e$ commerce $(\mathrm{X})$ terhadap keputusan pembelian (Y2) yang melalui brand image (Y1), daripada pengaruh langsung e-commerce terhadap keputusan pembelian tanpa melalui brand image.

Uji sobel merupakan alat analisis untuk menguji signifikansi dari hubungan antara variabel independen dengan variabel dependen yang dimediasi oleh variabel mediator. Hasil uji sobel dapat dilihat pada Tabel 9. 
Tabel 9.

Hasil Uji Sobel

\begin{tabular}{ccc}
\hline Sobel & Nilai & Keterangan \\
\hline $\mathrm{Z}$ & 3,0922 & Memediasi \\
Sig. & 0,000 & Signifikan \\
\hline
\end{tabular}

Sumber: Data Diolah, 2019

Berdasarkan Tabel 9. dapat dilihat bahwa Z sebesar 3,0922. Oleh karena Z hitung sebesar 3,0922 > 1,96 artinya brand image (Y1) merupakan variabel yang memediasi e-commerce terhadap keputusan pembelian konsumen pada hotel THE HAVEN Bali Seminyak atau dengan kata lain e-commerce berpengaruh secara tidak langsung terhadap keputusan pembelian melalui brand image.

Untuk melihat besarnya efek mediasi maka dilakukan uji VAF, hasil pengujian mediasi dengan metode VAF dalam penelitian ini telah memenuhi beberapa persyaratan yaitu pertama, pengaruh langsung ditemukan signifikan saat variabel brand image (Y1) belum dimasukkan ke dalam model. Kedua, setelah variabel brand image (Y1) dimasukkan ke dalam model, maka pengaruh tidak langsung ditemukan pula signifikan. Ketiga, melakukan kalkulasi nilai Variance Accounted For (VAF) untuk melihat besarnya variansi pada variabel dependen yang mampu dijelaskan oleh variabel independen melalui variabel mediator. Nilai VAF diperoleh dengan membandingkan besarnya pengaruh tidak langsung terhadap pengaruh total. Besarnya nilai VAF dapat dilihat pada Tabel 10 berikut:

Tabel 10.

\begin{tabular}{ccccc}
\multicolumn{5}{c}{ Hasil Uji VAF } \\
\hline $\begin{array}{c}\text { Pengaruh } \\
\text { Variabel }\end{array}$ & $\begin{array}{c}\text { Pengaruh Tidak } \\
\text { Langsung }\end{array}$ & $\begin{array}{c}\text { Pengaruh Total } \\
\text { VAF }\end{array}$ & Jenis Mediasi \\
\hline $\mathrm{X} \rightarrow$ Y2 & 0,173 & 0,656 & $26,4 \%$ & Mediasi Parsial \\
\hline Sumber: Data Diolah, 2019 & & & &
\end{tabular}

Karena nilai VAF (26,4 persen) lebih dari 20 persen, maka dapat dijelaskan bahwa variabel mediasi bersifat parsial. Maka hipotesis yang menyatakan bahwa brand image berperan dalam memediasi e-commerce terhadap keputusan pembelian diterima.

Pengujian pada hipotesis pengaruh e-commerce terhadap brand image menunjukkan bahwa e-commerce berpengaruh positif dan signifikan terhadap brand image. Hal ini memiliki makna bahwa semakin handal e-commerce (website) hotel THE HAVEN Bali Seminyak, maka persepsi konsumen mengenai merek hotel THE HAVEN Bail Seminyak akan semakin baik. Sebaliknya, apabila $e$ commerce (website) hotel tidak handal, maka persepsi konsumen mengenai merek hotel THE HAVEN Bali Seminyak akan tidak baik.

Penelitian ini menunjukkan bahwa semakin baik desain tampilan, akses, dan kecepatan website hotel THE HAVEN Bali Seminyak, serta semakin mudah proses pemesanan kamar hotel melalui website resmi hotel, maka akan membantu membentuk persepsi konsumen yang baik mengenai citra merek hotel THE HAVEN Bali Seminyak. Hasil penelitian ini mendukung temuan Gunawan et al. 
(2019) serta Kidane \& Sharma (2016) yang menyatakan bahwa e-commerce yang handal pada website mendorong terbentuknya brand image yang baik, sedangkan buruknya e-commerce pada website dapat menyebabkan konsumen memiliki persepsi brand image yang tidak baik.

Pengujian pada hipotesis pengaruh e-commerce terhadap keputusan pembelian menunjukkan bahwa e-commerce berpengaruh positif dan signifikan terhadap keputusan pembelian konsumen. Dengan demikian, semakin handal $e$ commerce (website) hotel THE HAVEN Bali Seminyak maka keputusan pembelian konsumen untuk kamar hotel THE HAVEN Bali Seminyak juga akan semakin tinggi. Hasil penelitian ini sesuai dengan penelitian sebelumnya yang dilakukan oleh Agustyan (2017), Putra \& Wulandari (2015) dan Xiao et al. (2019) yang menyatakan bahwa menyatakan bahwa e-commerce yang handal dapat meningkatkan keputusan konsumen dalam pembelian suatu produk.

Hasil hipotesis dari pengaruh brand image terhadap keputusan pembelian menunjukkan bahwa brand image berpengaruh positif dan signifikan terhadap keputusan pembelian. Dengan demikian, brand image yang yang baik mengenai hotel THE HAVEN Bali Seminyak, akan mampu meningkatkan keputusan pembelian konsumen. Hasil penelitian ini sesuai dengan hasil penelitian Kurniawan (2018), Rommy et al. (2018), Amron (2018), Habibah \& Sumiati (2016), Hapsoro \& Hafidh (2018), Roncancio et al. (2016), Lusiah et al. (2018), Suhaily \& Darmoyo (2017) dan Foster (2016) yang menunjukkan bahwa brand image yang baik dapat meningkatkan keputusan pembelian konsumen, begitu pula sebaliknya brand image yang tidak baik dapat menurunkan keputusan pembelian konsumen.

Hasil analisis hipotesis peran brand image memediasi hubungan e-commerce dengan keputusan pembelian menunjukkan bahwa brand image mampu memediasi secara signifikan pengaruh e-commerce terhadap keputusan pembelian. Hal tersebut memiliki arti bahwa semakin handal suatu e-commerce perusahaan, maka semakin tinggi pula keputusan pembelian, tingkat keputusan pembelian juga akan semakin meningkat karena dipengaruhi secara tidak langsung dengan brand image hotel THE HAVEN Bali Seminyak yang baik. Hasil penelitian ini sejalan dengan penelitian yang dilakukan oleh Bagus et al. (2018), Sanjiwani \& Suasana (2019) Iswara \& Jatra (2017), Ardana \& Rastini (2018) dan Eriza (2017) yang menyatakan bahwa brand image mampu memediasi pengaruh e-commerce terhadap keputusan pembelian karena e-commerce yang handal mampu meningkatkan brang image yang baik dengan begitu keputusan pembelian konsumen secara tidak langsung juga akan semakin meningkat.

\section{SIMPULAN}

E-commerce berpengaruh positif dan signifikan terhadap brand image. Hal ini berarti semakin handal e-commerce yang dimiliki oleh suatu perusahaan, maka akan semakin baik pula brand image yang tertanam di benak konsumen. Ecommerce berpengaruh positif dan signifikan terhadap keputusan pembelian konsumen. Hal ini berarti bahwa semakin handal e-commerce yang dimiliki perusahaan, maka semakin tinggi pula keputusan konsumen dalam melakukan pembelian. Brand image berpengaruh positif dan signifikan terhadap keputusan 
pembelian konsumen. Hal ini berarti bahwa semakin baik brand image yang dimiliki perusahaan, maka semakin tinggi pula keputusan konsumen untuk melakukan pembelian. Brand image mampu memediasi pengaruh e-commerce terhadap keputusan pembelian konsumen. Hal ini berarti brand image mampu memberikan dampak yang lebih besar pada e-commerce dalam memengaruhi keputusan pembelian konsumen.

Berdasarkan hasil penelitian, maka saran yang dapat diberikan adalah pihak hotel agar lebih memerhatikan kehandalan kecepatan e-commerce, yakni website resmi hotel THE HAVEN Bali Seminyak yang digunakan sebagai media untuk konsumen melakukan pemesanan kamar hotel karena berdasarkan penelitian, kecepatan website hotel THE HAVEN Bali Seminyak memiliki nilai rata-rata yang rendah dibandingkan dengan pernyataan variabel $e$-commerce yang lainnya. Cara mengatasi hal tersebut bisa dengan memperbaiki masalah-masalah pada website, seperti memperbaiki server web hosting, kualitas website, dan juga masalah jaringan, hal tersebut penting bagi pihak hotel karena penelitian google membuktikan bahwa website yang lambat berdampak negatif pada pertumbuhan pengunjung dan penjualan. Website yang lambat akan menaikkan presentase bounce rate atau orang yang baru membuka sudah langsung menutup website atau menekan tombol kembali (Nectar, 2019) maka pihak hotel harus meng-upgrade dan mempermudah semua elemen-elemen atau tools website yang dimiliki agar proses pemesanan kamar dapat dilakukan dengan mudah dan cepat sehingga konsumen akan merasa senang memesan kamar melalui website resmi hotel mengingat banyaknya pesaing situs penjualan online kamar hotel lainnya seperti traveloka, agoda, booking.com, dan sebagainya.

Pihak hotel THE HAVEN Bali Seminyak harus memperbaiki fasilitasfasilitas hotel yang dimiliki saat ini karena berdasarkan penelitian, pernyataan "harga yang ditawarkan hotel THE HAVEN Bali Seminyak sesuai dengan fasilitas yang didapat" mendapatkan nilai-nilai rata terendah, hal tersebut mengindikasikan bahwa fasilitas hotel saat ini sudah cukup baik, namun ada beberapa konsumen yang merasa belum sesuai dengan harga yang ditawarkan.

Untuk mempertahankan brand image hotel yang baik, pihak hotel harus terus memerhatikan fasilitas-fasilitas yang ditawarkan hotel untuk konsumen, merawat fasilitas yang ada dengan baik sehingga konsumen akan selalu nyaman menggunakannya, dan memberikan fasilitas yang lebih baik dari pesaing hotel sejenis lainnya agar konsumen memiliki pandangan merek yang positif serta tetap memilih hotel THE HAVEN Bali Seminyak untuk menginap. Pihak hotel THE HAVEN Bali Seminyak harus memerhatikan strategi pemasaran yang kuat untuk mampu membuat perbedaan yang signifikan terhadap pesaing sejenis lainnya, agar konsumen merasakan kelebihan dan keunikan yang ditawarkan hotel sehingga mampu membuat konsumen dalam mengambil keputusan untuk memesan kamar di hotel THE HAVEN Bali Seminyak, karena sebelum konsumen mengambil keputusan untuk benar-benar membeli, konsumen akan membanding-bandingkan hotel satu dengan lainnya dan mengumpulkan informasi sebanyak-banyaknya hingga konsumen mendapatkan hotel yang pas sesuai kebutuhannya untuk menginap. Pihak hotel harus mampu membuat pengalaman menginap konsumen menjadi senjata ampuh untuk penjualan kamar hotel, karena jika konsumen merasa 
puas menginap di hotel THE HAVEN Bali Seminyak maka dengan senang hati konsumen akan menceritakan pengalamannya kepada teman, keluarga, rekan kerja, bahkan menulis ulasan di media ulasan online, seperti tripadvisor dan hal tersebut mampu membangun brand image hotel yang positif secara tidak langsung, dengan demikian keputusan pembelian untuk kamar hotel THE HAVEN Bali Seminyak oleh konsumen dapat meningkat.

\section{REFERENSI}

Agustyan, F. (2017). Pengaruh E-commerce, Kualitas Produk, dan Brand Image terhadap Keputusan Pembelian pada Industri Ekonomi Kreatif (Studi pada UMKM Askha Jaya). Jurnal Manajemen Pemasaran, 1(1), 1-20.

Amron, A. (2018). The Influence of Brand Image, Brand Trust, Product Quality, and Price on the Consumer's Buying Decision of MPV Cars. European $\begin{array}{llll}\text { Scientific Journal, } & \text { ESJ, }\end{array}$ https://doi.org/10.19044/esj.2018.v14n13p228

Ardana, Y. A., \& Rastini, N. M. (2018). Peran Citra Merek Memediasi Pengaruh eWOM terhadap Minat Beli Smartphone Samsung di Kota Denpasar. E-Jurnal Manajemen Unud, 7(11), 5901-5929.

Arif, M. E. (2019). The Influence of Electronic Word of Mouth (EWOM), Brand Image, and Price on Re-Purchase Intention of Airline Customers. Journal of Applied Management, 17(2), 345-356.

Bagus, I., Ari, G., \& Santika, I. W. (2018). PERAN BRAND IMAGE DALAM MEMEDIASI PENGARUH ELECTRONIC WORD OF MOUTH TERHADAP NIAT BELI. E-Jurnal Manajemen Univeristas Udayana, 7(6), 3230-3257.

Baubonienè, Ž., \& Gulevičiūtè, G. (2015). E-commerce Factors Influencing Consumers' Online Shopping Decision. Social Technologies Journal, 5(1), 74-81.

Eriza, Z. N. (2017). Peran Mediasi Citra Merek dan Persepsi Risiko pada Hubungan antara Electronic Word of Mouth (E-WOM) dan Minat Beli (Studi pada Konsumen Kosmetik E-Commerce di Solo Raya). Jurnal Manajemen, 9(1), $14-24$.

Foster, B. (2016). Impact of Brand Image on Purchasing Decision on Mineral Water Product "Amidis." American Research Journal of Humanities and Social Scienes, 2(1), 1-11.

Fouratama, F., \& Arifin, Z. (2018). Pengaruh Citra Merek (Brand Image) terhadap Keputusan Pembelian. Jurnal Administrasi Bisnis, 56(1), 207-215. 
Ghoribi, K. A., \& Djoko, H. (2018). Pengaruh E-commerce, Kualitas Produk, dan Promosi terhadap Keputusan Pembelian (Studi pada Batik Mahkota Laweyan, Surakarta). Jurnal Sosial Dan Politik, 1(1), 1-8.

Gunawan, A. V, Linawati, P. D., \& Kartono, R. (2019). Factors That Influence Purchase Decision in E-Commerce in Jakarta and Tangerang. Business Review, 10(1), 1-9.

Habibah, U., \& Sumiati. (2016). The Influence Of Brand Awareness And Brand Image On Purchase Decision (Study On AQUA Consumers in Administrative Science Faculty Brawijaya University Class Of 2013). Jurnal Ekonomi Dan Bisnis, 1(1), 1-8.

Hapsoro, B. B., \& Hafidh, W. A. (2018). The Influence of Product Quality, Brand Image on Purchasing Decisions through Brand Trust as Mediating Variable. Management Analysis Journal, 7(4), 1-20. https://doi.org/10.15294/maj.v7i4.30407

Iswara, I. G. A. D., \& Jatra, I. M. (2017). Peran Brand Image Dalam Memediasi Pengaruh Electronic Word of Mouth Terhadap Purchase Intention (Studi Kasus Pada Produk Smartphone Samsung di Kota Denpasar). E-Jurnal Manajemen Unud, 6(8), 3991 - 4018.

Kidane, T. T., \& Sharma, R. R. . (2016). Factor Affecting Consumers' Purchase Decision through E-Commerce. Industrial Engineering and Operations Management Journal, 1(1), 159-165.

Kurniawan, F. (2018). Pengaruh Citra Merek terhadap Keputusan Pembelian. Jurnal Administrasi Bisnis, 5(1), 75 - 81.

Lin, C. T. L., \& Chuang, S. . (2018). The Importace of Brand Image on Consumer Purchase Attitude: A Case Study of E-Commerce in Taiwan. Journal of Business and Economics, 13(3), 91-104.

Lubis, D. I. D., \& Hidayat, R. (2017). Pengaruh Citra Merek dan Harga terhadap Keputusan Pembelian pada Sekolah Tinggi Ilmu Manajemen Sukma Medan. Jurnal Ilman, 5(1), 15-24. https://doi.org/10.4135/9781412983907.n1598

Lusiah, M., Noviantoro, D., \& Halim, L. T. (2018). The Effect of Endorsement and Brand Image on Purchase Decision of Online Culinary Product. Advances in Economics, Business and Management Research (AEBMR), 46(1), 530-533. https://doi.org/10.2991/ebic-17.2018.83

Moh, N. B. H. H. (2018). Effect of Brand Image and Price Perception on Purchase Decision. Journal of Business and Management, 20(8), 76-81. 
Puspitasari, N. B. (2018). Consumer's Buying Decision-Making Process in Ecommerce. E3S Web of Conferences, 1(1), 1-6.

Putra, H. P., \& Wulandari, A. (2015). Pengaruh Penerapan E-commerce terhadap Keputusan Pembelian. Jurnal Ecodemica, 3(2), 1-20.

Rommy, A. S. N., Moh, N. B. H. H., \& Nur, A. R. Y. N. (2018). Effect Of Brand Image And Price Perception On Purchase Decision. Journal of Business and Management, 20(8), 76-81. https://doi.org/10.9790/487X-2008027681

Roncancio R, Ginna \& Sáenz G, C. (2016). THE EFFECT OF BRAND IMAGE, PRODUCT QUALITY AND PRICE TOWARD PURCHASE DECISION. IOSR Journal of Economics and Finance, 3(1), 56. https://doi.org/https://doi.org/10.3929/ethz-b-000238666

Sanjiwani, N. M. D., \& Suasana, I. G. A. K. G. (2019). Peran Brand Image Dalam Memediasi Pengaruh Kualitas Produk Terhadap Keputusan Pembelian. EJurnal Manajemen Universitas Udayana, 8(11), 6721. https://doi.org/10.24843/ejmunud.2019.v08.i11.p17

Setiadi, I. G. N. B. H. I. M., \& Ekawati, N. W. (2019). Brand Image Memediasi Kualitas Produk terhadap Keputusan Pembelian Produk Smartphone Oppo di Kota Denpasar. E-Jurnal Manajemen, 8(1), 7102-7131.

Shahjee, R. (2016). The Impact of Electronic Commerce on Business Organization. International Journal of Management and Applied Science, 2(8), 58-61. Retrieved from www.srjis.com

Srisadono, W. (2018). Strategi Perusahaan E-commerce Membangun Brand Community di Media Sosial dalam Meningkatkan Omset Penjualan. Jurnal Pustaka Komunikasi, 1(1), 167-179.

Suhaily, L., \& Darmoyo, S. (2017). Effect of product quality, perceived price and brand image on purchase decision mediated by customer trust (study on japanese brand electronic product). Jurnal Manajemen, 21(2), 179-194. https://doi.org/10.24912/jm.v21i2.230

Xiao, L., Guo, F., Yu, F., \& Liu, S. (2019). The effects of online shopping context cues on consumers' purchase intention for cross-border E-Commerce sustainability. Sustainability (Switzerland), 11(10), 1-24. https://doi.org/10.3390/su11102777

Yasmin, A. (2017). Impact of Brand Image on Consumers' Purchase Decision. International Journal of Research in Social Sciences, 7(10), 627. 
E-Jurnal Manajemen, Vol. 9, No. 6, 2020 : 2268-2287

Zhang, Y. (2015). The Impact of Brand Image on Consumer Behaviour: A Literature Review. Open Journal of Business and Management, 3(1), 58-62. 